\title{
Developmental Effects of Endothelin-1 on the Pulmonary Circulation in Sheep
}

\author{
JACKSON WONG, PAULA A. VANDERFORD, JEFFREY R. FINEMAN, AND \\ SCOTT J. SOIFER \\ Department of Pediatrics and the Cardiovascular Research Institute, University of California \\ San Francisco, San Francisco, California 94143
}

\begin{abstract}
Endothelin-1 (ET-1) is a polypeptide that has potent hemodynamic effects on the pulmonary circulation. To determine whether there are changes in these effects with increasing postnatal age, we investigated the effects of ET-1 $(250 \mathrm{ng} / \mathrm{kg})$ at rest and during pulmonary hypertension in eight lambs (<1 wk old) and 11 juvenile sheep (6-12 mo old). At rest, ET-1 did not change pulmonary arterial pressure in lambs, but increased pulmonary arterial pressure by $64.0 \pm 37.5 \%(p<0.05)$ in sheep. During pulmonary hypertension, ET-1 produced greater decreases in pulmonary arterial pressure in lambs than in sheep $(26.6 \pm$ $3.4 \%$ versus $18.7 \pm 8.3 \%, p<0.05$ ). In juvenile sheep, the increase in resting pulmonary arterial pressure produced by ET- 1 was inhibited by meclofenamic acid, an inhibitor of prostaglandin synthesis $(40.3 \pm 9.9 \%$ versus $2.3 \pm 4.7 \%$, $p<0.05)$; during pulmonary hypertension, the decrease in
\end{abstract}

ABSTRACT

pulmonary arterial pressure produced by ET-1 was inhibited by $\mathbf{N}^{\omega}$-nitro-L-arginine, an inhibitor of endotheliumderived nitric oxide synthesis $(21.4 \pm 10.7 \%$ versus $8.0 \pm$ $3.6 \%, p<0.05)$ and by glybenclamide, an ATP-dependent potassium-channel blocker $(18.8 \pm 8.4 \%$ versus $4.0 \pm$ $4.4 \%, p<0.05)$. The hemodynamic effects of ET- 1 on the pulmonary circulation are dependent on postnatal age. Pulmonary vasoconstriction is mediated by prostaglandin production, and pulmonary vasodilation is mediated, in part, by release of endothelium-derived nitric oxide and activation of ATP-dependent potassium channels. (Pediatr Res 36: 394-401, 1994)

ET-1, endothelin-1

\section{Abbreviations}

EDNO, endothelium-derived nitric oxide
ET-1, an endothelium-derived polypeptide, has potent vasoactive properties that may mediate vascular tone (1). Studies of ET-1 on the pulmonary circulation in fetal, newborn, and adult animals demonstrate that ET-1 produces a wide range of hemodynamic effects, which include vasodilation alone, vasoconstriction alone, or transient vasodilation followed by vasoconstriction (2-14). However, the reasons why ET-1 produces this wide range of hemodynamic effects are unknown.

After birth, there are extensive structural and physiologic changes in the pulmonary circulation (15). For example, there are developmental changes in pulmonary vascular receptors and their secondary messengers that mediate physiologic responses (16-19). Recent in vitro data suggest that the effects of ET-1 on the pulmonary circulation may also change with increasing age from

Received November 19, 1993; accepted May 16, 1994.

Correspondence: Scott J. Soifer M.D., M-646, University of California, San Francisco, CA 94143-0106.

Supported by Grant HL 35518 from the National Heart, Lung and Blood Institute and by the University of California San Francisco Academic Committee on Research. pulmonary vasodilation to pulmonary vasoconstriction $(20,21)$.

This study has two purposes. First, to investigate whether postnatal age alters the hemodynamic effects of ET-1 on the pulmonary circulation in the intact sheep, we compared the effects of intrapulmonary injections of ET-1 in newborn lambs ( $<1$ wk old) and juvenile sheep (6-12 mo old), both at rest and during pulmonary hypertension. Second, to determine the mechanism of ET-1induced responses, we compared the effects of intrapulmonary injections of ET-1 in juvenile sheep before and during prostaglandin synthesis inhibition, EDNOsynthesis inhibition, and potassium-channel blockade.

\section{METHODS}

\section{Surgical Preparation}

The surgical preparation was the same for both newborn lambs and juvenile sheep. The lambs $(<1$ wk old $)$ and sheep (6-12 mo old, not time bred) were sedated with ketamine hydrochloride $(5 \mathrm{mg} / \mathrm{kg})$ by intramuscular injection, intubated with a $4.5-$ or $10.0-\mathrm{mm}$ outer diameter endotracheal tube, and mechanically ventilated with a 
Harvard volume-cycled animal ventilator. General anesthesia was then induced by having the animal breathe a mixture of oxygen and halothane (1-2\%). Under local anesthesia with $1 \%$ lidocaine hydrochloride, polyvinyl catheters were placed in an artery and vein of each hind leg. These catheters were advanced to the descending aorta and the inferior vena cava, respectively. A left lateral thoracotomy was performed in the fourth intercostal space. Polyvinyl catheters were then placed in the internal thoracic artery and vein and advanced to the ascending aorta and right atrium, respectively. The pericardium was incised along the main pulmonary trunk. Three Teflon cannulas attached to polyvinyl catheters were then inserted, two into the main pulmonary artery and one into the left atrium. A precalibrated transonic flow transducer (Transonic Systems, Ithaca, NY) was placed around the left pulmonary artery to measure left pulmonary blood flow. In the lamb, the ductus arteriosus was visualized and ligated. A chest tube was placed in the pleural space for drainage. The thoracotomy incision was closed in layers. The catheters were filled with heparin sodium, plugged, and brought to the skin along with the transducer cable, where they were protected in a pouch secured to the animal's flank. After recovery from anesthesia, the animals were weaned from mechanical ventilation, extubated, and returned to their cages. At least 2 d were allowed for recovery. Daily, the chest tube was aspirated and the catheters were flushed with heparin sodium. The lambs were given a daily intramuscular injection of $250000 \mathrm{U}$ of penicillin $\mathrm{G}$ and $25 \mathrm{mg}$ of gentamicin. The sheep were given a daily intramuscular injection of 1 million $U$ of penicillin $G$ procaine and $50 \mathrm{mg}$ of gentamicin suspension. For the first $24 \mathrm{~h}$ after surgery, buprenorphine hydrochloride (Reckitt \& Colman Pharmaceuticals, Richmond, VA; $0.01 \mathrm{mg} / \mathrm{kg}$ ) was administrated intramuscularly to prevent postoperative pain. This surgical preparation was similar to those previously published from our laboratory (22). All protocols were approved by the Committee on Animal Research, University of California, San Francisco.

\section{Drug Preparation}

ET-1 (0.5 mg), (Peptides International, Inc., Louisville, $\mathrm{KY}$ ) was suspended in $10 \mathrm{~mL}$ of sterile water and stored at $-20^{\circ} \mathrm{C}$. Immediately before administration, each ET-1 dose was measured and diluted to $1 \mathrm{~mL}$ with $0.9 \%$ saline. U46619 (9,11-dideoxy-9-epoxymethanoprostaglandin $\mathrm{F}_{2 \alpha}$; Sigma Chemical Co., St. Louis, MO) was suspended in $95 \%$ ethanol and stored at $-20^{\circ} \mathrm{C}$. Immediately before administration, $100 \mu \mathrm{g}$ were dissolved in $20 \mathrm{~mL}$ of $0.9 \%$ saline. Meclofenamic acid (Sigma Chemical Co.) was prepared for bolus injection by dissolving $70 \mathrm{mg}$ in $10.6 \mathrm{~mL}$ of $0.9 \%$ saline, $0.4 \mathrm{~mL}$ of $\mathrm{Na}_{2} \mathrm{CO}_{3}(7.15 \mathrm{~g} / \mathrm{L})$, and $8 \mathrm{~mL}$ of distilled water. For the continuous infusion, $70 \mathrm{mg}$ of meclofenamic acid was dissolved in $58 \mathrm{~mL}$ of $0.9 \%$ saline, $2 \mathrm{~mL}$ of $\mathrm{Na}_{2} \mathrm{CO}_{3}(7.15$ $\mathrm{g} / \mathrm{L})$, and $40 \mathrm{~mL}$ of distilled water. $\mathrm{N}^{\omega}$-nitro-L-arginine
(Sigma Chemical Co.) was suspended in $0.9 \%$ saline. Cromakalim (BRL-38227, SmithKline Beecham Pharmaceuticals, Surrey, England) and acetylcholine chloride (Iolab Corporation, Claremont, CA) were suspended in $0.9 \%$ saline. Glybenclamide (Sigma Chemical Co.) was suspended in distilled water and titrated to a $\mathrm{pH}$ of 12.0 by the addition of $1 \mathrm{~N} \mathrm{NaOH}$. All solutions were prepared on the day of the study and kept on ice until administrated.

\section{Experimental Protocol}

To determine whether postnatal development alters the hemodynamic effects of ET-1, we compared the effects of ET-1 on the pulmonary circulation at rest and during pulmonary hypertension in lambs and sheep. To determine the mechanism of ET-1's hemodynamic effects in sheep, we compared the effects of ET-1 before and during the infusion of meclofenamic acid at rest, and before and during the infusion of $\mathbf{N}^{\omega}$-nitro-L-arginine, glybenclamide, and meclofenamic acid during pulmonary hypertension induced by the infusion of U46619 (a thromboxane $\mathrm{A}_{2}$ mimic). All studies were performed with the newborn lambs and juvenile sheep resting quietly in a sling or a cage and spontaneously breathing room air. We have previously shown that low to moderate doses of ET-1 $(50-1000 \mathrm{ng} / \mathrm{kg})$ do not change mean pulmonary arterial pressure or pulmonary vascular resistance in resting newborn lambs, and very large doses of ET-1 (2000 $\mathrm{ng} / \mathrm{kg}$ ) produce pulmonary vasoconstriction $(14,23)$. The dose of ET-1 used in the present study $(250 \mathrm{ng} / \mathrm{kg})$ was chosen after preliminary studies in juvenile sheep showed that higher doses $(500 \mathrm{ng} / \mathrm{kg}$ ) produced marked decreases in pulmonary blood flow and hemodynamic instability. In addition, preliminary studies also showed that a 24-h recovery period was necessary to produce consistent hemodynamic responses to repeated doses of ET-1 in the juvenile sheep. Therefore, the lambs and sheep were rested at least $24 \mathrm{~h}$ between injections of ET-1, and dose response curves were not performed. Bolus injections of ET-1 were used after preliminary studies in lambs showed that continuous infusions produced no hemodynamic effects. Each lamb underwent two studies (at rest and U46619); each sheep underwent three to four studies (at rest, U46619, and one to two mechanism studies). Only juvenile sheep received infusions of $\mathrm{N}^{\omega}$-nitro-Larginine, glybenclamide, or meclofenamic acid.

ET-1 injections at rest. In eight lambs and 10 sheep, baseline measurements of the hemodynamic variables (pulmonary arterial pressure, systemic arterial pressure, left pulmonary blood flow, heart rate, and left and right atrial pressures) and systemic arterial blood gases and $\mathrm{pH}$ were made. ET-1 $(250 \mathrm{ng} / \mathrm{kg})$ was injected into the pulmonary artery. The dose was injected in less than $10 \mathrm{~s}$, followed by a $2-\mathrm{mL}$ flush of $0.9 \%$ saline. The hemodynamic variables and systemic arterial blood gases and $\mathrm{pH}$ were measured at the maximum change in pulmonary artery pressure (ET-1). At the end of the study, the sheep were returned to their cages. 
ET-1 injections during U46619-induced pulmonary hypertension. After a 24-h recovery, eight lambs and 11 sheep had baseline measurements of the hemodynamic variables and systemic arterial blood gases made. Then, an infusion of $\mathrm{U} 46619$ was begun into the inferior vena cava and continued throughout the study period. The dose $(\sim 2$ $\mu \mathrm{g} / \mathrm{kg} / \mathrm{min}$ ) was titrated to achieve a mean pulmonary arterial pressure 2 times baseline. After $10 \mathrm{~min}$ of steady state pulmonary hypertension, all variables were measured (U46619). ET-1 $(250 \mathrm{ng} / \mathrm{kg})$ was injected into the pulmonary artery and the hemodynamic variables were measured as above (U46619 + ET-1). The infusion of U46619 was then stopped, and the sheep were returned to their cages.

ET-1 injections during meclofenamic acid infusions, $N^{\omega}$. nitro-L-arginine infusions, and glybenclamide infusions. In juvenile sheep, the mechanism of ET-1's pulmonary vasoconstricting effects at rest was assessed by comparing the effects of the initial injection of ET-1 and the injection during the infusion of meclofenamic acid (a prostaglandin synthesis inhibitor). Conversely, the mechanism of ETl's pulmonary vasodilating effects was assessed by comparing the effects of the initial injection of ET-1 during pulmonary hypertension induced by $\mathrm{U} 46619$ and the injection of ET-1 during the infusion of $\mathrm{N}^{\omega}$-nitro-L-arginine, glybenclamide, or meclofenamic acid, all during pulmonary hypertension induced by U46619. A 24-h recovery period was allowed between each infusion.

Meclofenamic acid infusions at rest. In five sheep, baseline measurements were made. Then, meclofenamic acid $(10 \mathrm{mg} / \mathrm{kg})$ was infused into the pulmonary artery over 15 min, followed by a $1.0 \mathrm{mg} / \mathrm{kg} / \mathrm{h}$ infusion for at least $4 \mathrm{~h}$. Previous studies showed that this cumulative dose of meclofenamic acid inhibits the production of prostaglandins (24). After $4 \mathrm{~h}$ of the meclofenamic acid infusion, all variables were measured and ET-1 was injected as described above.

$N^{\omega}$-nitro-L-arginine infusions during pulmonary hypertension. In six sheep, baseline measurements were made. An infusion of U46619 was infused i.v. to increase mean pulmonary arterial pressure 2 times baseline. After 10 min of steady state pulmonary hypertension, acetylcholine $(0.5 \mu \mathrm{g} / \mathrm{kg}$, an EDNO-dependent vasodilator) was injected and all variables were measured. The U46619 infusion was then stopped. After a 30-min recovery, $\mathrm{N}^{\omega}$-nitro-L-arginine $(1 \mathrm{mg} / \mathrm{kg} / \mathrm{min})$ was infused i.v. for 120 min. Previous studies showed that this cumulative dose of $\mathrm{N}^{\omega}$-nitro-L-arginine attenuates the pulmonary vasodilating effects of acetylcholine and other endotheliumdependent vasodilators (22). Then, pulmonary hypertension was induced by U46619 as described. After $10 \mathrm{~min}$ all variables were measured, and the acetylcholine and ET-1 injections were repeated.

Glybenclamide infusions during pulmonary hypertension. In six sheep, baseline measurements were made and U46619 was infused to induce pulmonary hypertension. After 10 min of steady state pulmonary hypertension, cromakalim $(50 \mu \mathrm{g} / \mathrm{kg}$, a potassium-channel activator) was injected and all variables were measured. The U46619 infusion was then stopped. After a 30-min recovery, glybenclamide $(5 \mathrm{mg} / \mathrm{kg})$ or distilled water with a $\mathrm{pH}$ of 12.0 (vehicle), was infused i.v. for $60 \mathrm{~min}$. Then U46619 was infused to induce pulmonary hypertension. After $10 \mathrm{~min}$ all variables were measured, and the cromakalim and ET-1 injections were repeated. The specific doses of cromakalim and glybenclamide were chosen because previous studies showed that $50 \mu \mathrm{g} / \mathrm{kg}$ of cromakalim produces potent pulmonary vasodilation and that the cumulative dose of glybenclamide used attenuates the pulmonary vasodilating effects of potassiumchannel activators $(14,25)$.

Meclofenamic acid infusions during pulmonary hypertension. In six juvenile sheep, baseline measurements were measured. Meclofenamic acid was infused i.v. as described above. After $4 \mathrm{~h}$ of the meclofenamic acid infusion, U46619 was infused as described above. After 10 min of steady state pulmonary hypertension, all variables were measured, and ET-1 was injected.

\section{Measurements}

Pulmonary and systemic arterial pressures and left and right atrial pressures were measured by Statham P23Db pressure transducers (Statham Instruments, Hato Rey, Puerto Rico). Mean pressures were obtained by electrical integration. Heart rate was measured by a cardiotachometer triggered from the phasic systemic arterial pressure pulse wave. Left pulmonary artery blood flow was measured on an ultrasonic flow meter (Transonic Systems). All hemodynamic variables were continuously recorded on a Gould multichannel electrostatic recorder (Gould Inc., Cleveland, $\mathrm{OH}$ ). Systemic arterial blood gases and $\mathrm{pH}$ were measured on a Corning $158 \mathrm{pH} / \mathrm{blood}$ gas analyzer (Corning Medical and Scientific, Medfield, MA). Left pulmonary vascular resistance was calculated as mean pulmonary arterial pressure minus left atrial pressure divided by left pulmonary blood flow.

\section{Statistical Analysis}

The means \pm SD were calculated for the hemodynamic variables and systemic arterial blood gases and $\mathrm{pH}$ during all experimental conditions. The effects of U46619 on these variables were compared with their respective baseline by the paired $t$ test. The effects of each vasoactive agent (ET-1, meclofenamic acid, acetylcholine, $\mathrm{N}^{\omega}$ nitro-L-arginine, cromakalim, and glybenclamide) on these variables were compared with their previous steady state condition by the paired $t$ test using the Bonferroni correction when necessary. The percent change in the variables produced by ET-1 at rest and during U46619induced pulmonary hypertension between newborn lambs and juvenile sheep were compared by the unpaired $t$ test. The percent change in the hemodynamic variables produced by ET-1 at rest was compared with the percent change produced during infusion of meclofenamic acid at rest by the paired $t$ test. The percent change in the 
Table 1. Hemodynamic effects of ET-I in newborn lambs and juvenile sheep at rest*

\begin{tabular}{|c|c|c|c|c|}
\hline & \multicolumn{2}{|c|}{ Newborn lambs } & \multicolumn{2}{|c|}{ Juvenile sheep } \\
\hline & REST & ET-1 & REST & ET-1 \\
\hline Pulmonary arterial pressure $(\mathrm{mm} \mathrm{Hg}$ ) & $19.9 \pm 2.9$ & $19.3 \pm 2.9$ & $16.5 \pm 2.6$ & $27.2 \pm 8.5 t$ \\
\hline Left pulmonary vascular resistance ( $\mathrm{mm} \mathrm{Hg} / \mathrm{mL} / \mathrm{min}$ ) & $0.029 \pm 0.007$ & $0.030 \pm 0.006$ & $0.008 \pm 0.002$ & $0.044 \pm 0.078 \dagger$ \\
\hline Systemic arterial pressure $(\mathrm{mm} \mathrm{Hg}$ ) & $78.3 \pm 5.2$ & $87.0 \pm 7.2 \dagger$ & $95.4 \pm 9.6$ & $112.6 \pm 15.0 \dagger$ \\
\hline Left pulmonary blood flow $(\mathrm{mL} / \mathrm{min})$ & $643.6 \pm 107.9$ & $594.4 \pm 62.9$ & $1180.0 \pm 355.3$ & $952.3 \pm 415.4 \dagger$ \\
\hline Heart rate (bpm) & $222.5 \pm 29.5$ & $208.5 \pm 30.8 \dagger$ & $138.6 \pm 40.2$ & $132.5 \pm 51.2$ \\
\hline Left atrial pressure $(\mathrm{mm} \mathrm{Hg}$ ) & $2.1 \pm 2.5$ & $2.4 \pm 2.8$ & $6.3 \pm 2.6$ & $8.6 \pm 3.1 \dagger$ \\
\hline Right atrial pressure $(\mathrm{mm} \mathrm{Hg}$ ) & $0.2 \pm 0.4$ & $0.8 \pm 1.1$ & $4.1 \pm 2.5$ & $5.8 \pm 3.5 t$ \\
\hline
\end{tabular}

* Values are mean \pm SD for eight newborn lambs and 10 juvenile sheep.

$\dagger p<0.05$ is previous rest column.

hemodynamic variables produced by ET-1, acetylcholine, and cromakalim during U46619-induced pulmonary hypertension was compared with the percent change produced during the infusion of $\mathrm{N}^{\omega}$-nitro-L-arginine, glybenclamide, or meclofenamic acid by the paired $t$ test. The means \pm SD were calculated for left pulmonary vascular resistance and compared by the Wilcoxon signed-rank test or the Mann-Whitney test; $p<0.05$ was considered statistically significant.

\section{RESULTS}

\section{ET-1 Injections at Rest}

In newborn lambs, ET-1 did not change mean pulmonary arterial pressure or left pulmonary vascular resistance (Table 1). In juvenile sheep, ET-1 increased mean pulmonary arterial pressure and left pulmonary vascular resistance $(p<0.05)$ (Table 1). The increase in pulmonary arterial pressure occurred within $10 \mathrm{~s}$ of the injection and lasted 102.2 $\pm 41.2 \mathrm{~s}$. The injection of ET-1 did not change systemic arterial blood gases and $\mathrm{pH}$ in newborn lambs. ET-1 slightly increased systemic arterial $\mathrm{pH}$ (from $7.50 \pm 0.05$ to $7.52 \pm 0.05$ units, $p<0.05$ ) and decreased $\mathrm{PaO}_{2}$ (from $12.2 \pm 3.3$ to $11.0 \pm 2.5 \mathrm{kPa}, p<0.05$ ) in juvenile sheep. The percent increase in pulmonary arterial pressure and pulmonary vascular resistance induced by ET-1 was greater in juvenile sheep than in newborn lambs $(p<0.05)$ (Fig. 1).

\section{ET-1 Injections during U46619-Induced Pulmonary Hypertension}

During steady state pulmonary hypertension, ET-1 decreased mean pulmonary arterial pressure and left pulmonary vascular resistance in both lambs and sheep $(p<$ 0.05 ) (Table 2). The decrease in pulmonary arterial pressure occurred within $10 \mathrm{~s}$ of the injection and lasted 214.0 $\pm 29.7 \mathrm{~s}$ in the lamb and $55.5 \pm 35.0 \mathrm{~s}$ in the sheep. The injection of ET-1 did not change systemic arterial blood gases and $\mathrm{pH}$ in all animals. The percent decrease in pulmonary arterial pressure produced by ET-1 in lambs was greater than in sheep $(26.6 \pm 3.4 \%$ versus $18.7 \pm$ $8.3 \%, p<0.05)$. The percent decrease in left pulmonary vascular resistance induced by ET-1 was similar, but the absolute decrease in left pulmonary vascular resistance produced in lambs was greater than that in sheep $(0.052 \pm$ 0.01 versus $0.024 \pm 0.01 \mathrm{~mm} \mathrm{Hg} / \mathrm{mL} / \mathrm{min}, p<0.05$ ). In addition, in five of the sheep, the decrease in pulmonary arterial pressure and pulmonary vascular resistance was followed by an increase in pulmonary arterial pressure (from $33.2 \pm 2.8$ to $36.4 \pm 1.7 \mathrm{~mm} \mathrm{Hg}, p<0.05$ ) and in left pulmonary vascular resistance (from $0.034 \pm 0.015$ to $0.055 \pm 0.008 \mathrm{~mm} \mathrm{Hg} / \mathrm{mL} / \mathrm{min}$ ). There were no differences in the baseline hemodynamic variables, systemic arterial blood gases and $\mathrm{pH}$, sex, or weight between the sheep with pulmonary vasodilation alone and the sheep with a biphasic response.

ET-1 Injections during Meclofenamic Acid Infusions, $\mathbf{N}^{\mathbf{\omega}}$-Nitro-L-Arginine Infusions, and Glybenclamide Infusions

Meclofenamic acid infusions at rest. The infusion of meclofenamic acid did not change any of the hemodynamic variables. During the infusion of meclofenamic acid, ET-1 did not change mean pulmonary arterial pressure or left pulmonary vascular resistance (Fig. 2).

$N^{\omega}{ }^{\omega}$-nitro-L-arginine infusions during pulmonary hypertension. The infusion of $\mathrm{N}^{\omega}$-nitro-L-arginine increased base-

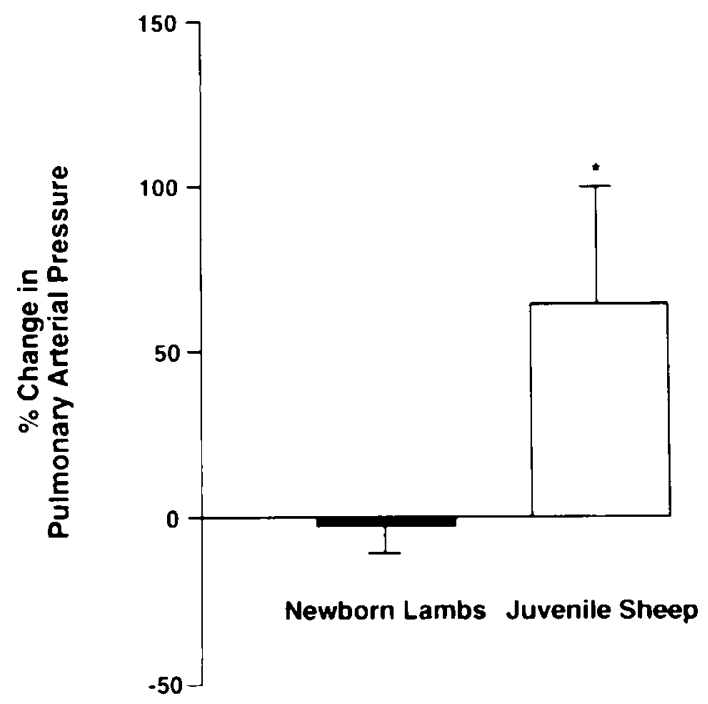

Figure 1. At rest, ET-1 $(250 \mathrm{ng} / \mathrm{kg})$ increases pulmonary arterial pressure in juvenile sheep but not in newborn lambs. Values are mean \pm $\mathrm{SD} ; n=8$ newborn lambs and 10 juvenile sheep. ${ }^{*}, p<0.05 v$ s newborn lambs. 
Table 2. Hemodynamic effects of ET-1 in newborn lambs and juvenile sheep during U46619-induced pulmonary hypertension*

\begin{tabular}{|c|c|c|c|c|c|c|}
\hline & \multicolumn{3}{|c|}{ Newborn lambs } & \multicolumn{3}{|c|}{ Juvenile sheep } \\
\hline & U46619 & $\mathrm{U} 46619+\mathrm{ET}-1$ & $\%$ change & U46619 & $\mathrm{U} 46619+\mathrm{ET}-1$ & $\%$ change \\
\hline Pulmonary arterial pressure $(\mathrm{mm} \mathrm{Hg}$ ) & $34.7 \pm 4.3$ & $25.4 \pm 2.8 \dagger$ & $-26.6 \pm 3.4$ & $34.6 \pm 3.9$ & $28.0 \pm 3.0 \dagger$ & $-18.7 \pm 8.3 \ddagger$ \\
\hline $\begin{array}{l}\text { Left pulmonary vascular resistance } \\
(\mathrm{mm} \mathrm{Hg} / \mathrm{mL} / \mathrm{min})\end{array}$ & $0.067 \pm 0.016$ & $0.051 \pm 0.015 \dagger$ & $-24.6 \pm 7.9$ & $0.032 \pm 0.011$ & $0.025 \pm 0.010 \dagger$ & $-22.3 \pm 16.9$ \\
\hline Systemic arterial pressure $(\mathrm{mm} \mathrm{Hg})$ & $89.4 \pm 22.2$ & $101.4 \pm 26.9 \dagger$ & $13.2 \pm 5.1$ & $106.2 \pm 8.7$ & $115.1 \pm 12.5 \dagger$ & $8.4 \pm 8.5$ \\
\hline Left pulmonary blood flow $(\mathrm{mL} / \mathrm{min})$ & $504.3 \pm 68.1$ & $461.4 \pm 82.1$ & $-8.8 \pm 6.0$ & $920.0 \pm 325.5$ & $851.1 \pm 383.1$ & $-9.1 \pm 13.5$ \\
\hline Heart rate $(\mathrm{bpm})$ & $208.7 \pm 48.7$ & $186.7 \pm 51.6 \dagger$ & $-10.7 \pm 10.4$ & $166.7 \pm 33.1$ & $160.0 \pm 31.6$ & $-3.3 \pm 13.3$ \\
\hline Left atrial pressure $(\mathrm{mm} \mathrm{Hg})$ & $2.5 \pm 1.3$ & $4.5 \pm 2.1$ & $164.5 \pm 290.6$ & $8.3 \pm 2.4$ & $10.0 \pm 3.0 \dagger$ & $20.7 \pm 13.6$ \\
\hline Right atrial pressure $(\mathrm{mm} \mathrm{Hg})$ & $1.0 \pm 0.9$ & $1.5 \pm 1.4$ & $62.5 \pm 94.6$ & $7.6 \pm 2.4$ & $8.1 \pm 2.3$ & $7.6 \pm 11.4$ \\
\hline
\end{tabular}

*Values are mean \pm SD for eight newborn lambs and 11 juvenile sheep.

$\dagger p<0.05$ vs previous U46619 column.

$\ddagger p<0.05$ vs \% change (newborn lambs).

line pulmonary arterial pressure (from $16.8 \pm 1.6$ to 25.8 $\pm 5.9 \mathrm{~mm} \mathrm{Hg}, p<0.05)$ and pulmonary vascular resistance (from $0.009 \pm 0.003$ to $0.022 \pm 0.010 \mathrm{~mm} \mathrm{Hg} / \mathrm{mL}$ / min, $p<0.05$ ). During the infusions of $\mathrm{N}^{\omega}$-nitro-L-
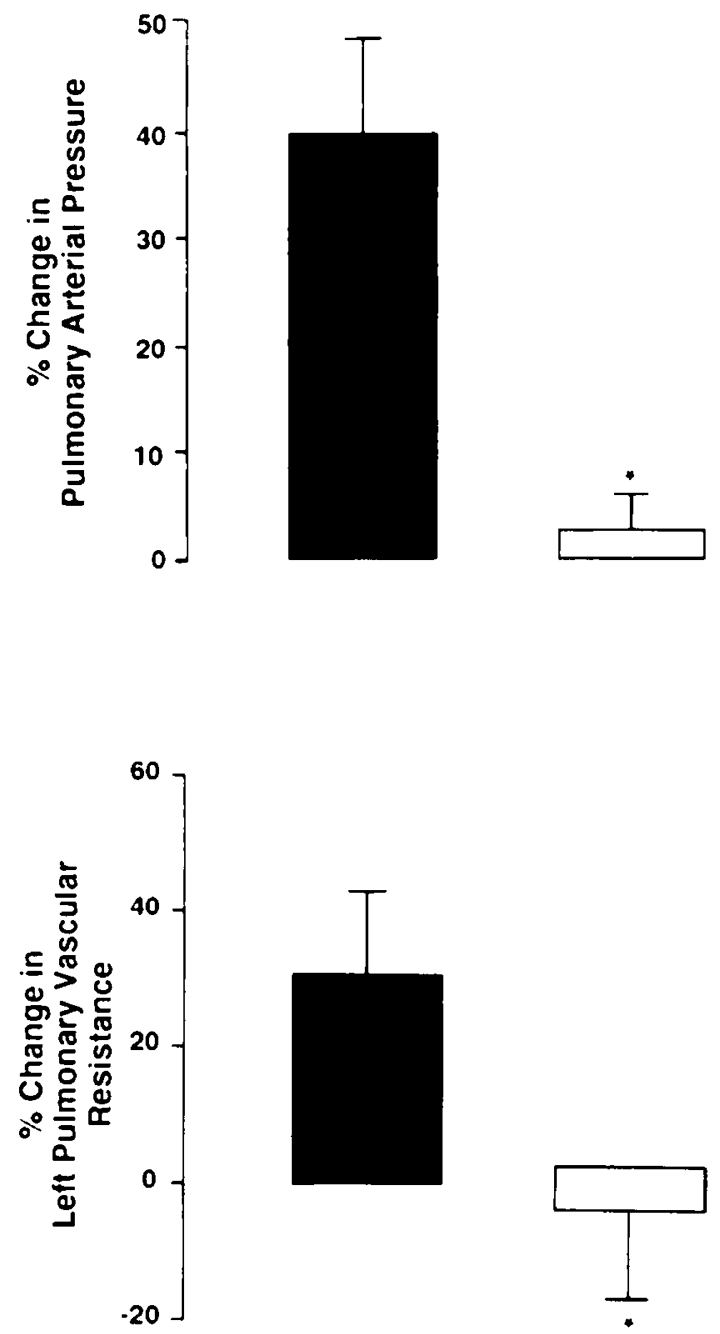

ET-1

\section{Meclofenamic Acid} + ET-1

Figure 2. At rest, the increase in mean pulmonary arterial pressure (top) and left pulmonary vascular resistance (bottom) induced by ET-1 $(250 \mathrm{ng} / \mathrm{kg})$ is blocked by meclofenamic acid. Values are mean $\pm \mathrm{SD} ; n$ $=5$ juvenile sheep. ${ }^{*}, p<0.05 v s$ ET-1. arginine and $\mathrm{U} 46619$, the percent decrease in both mean pulmonary arterial pressure and left pulmonary vascular resistance induced by ET-1 were significantly attenuated (Fig. 3). Similarly, the percent decrease in mean pulmo-
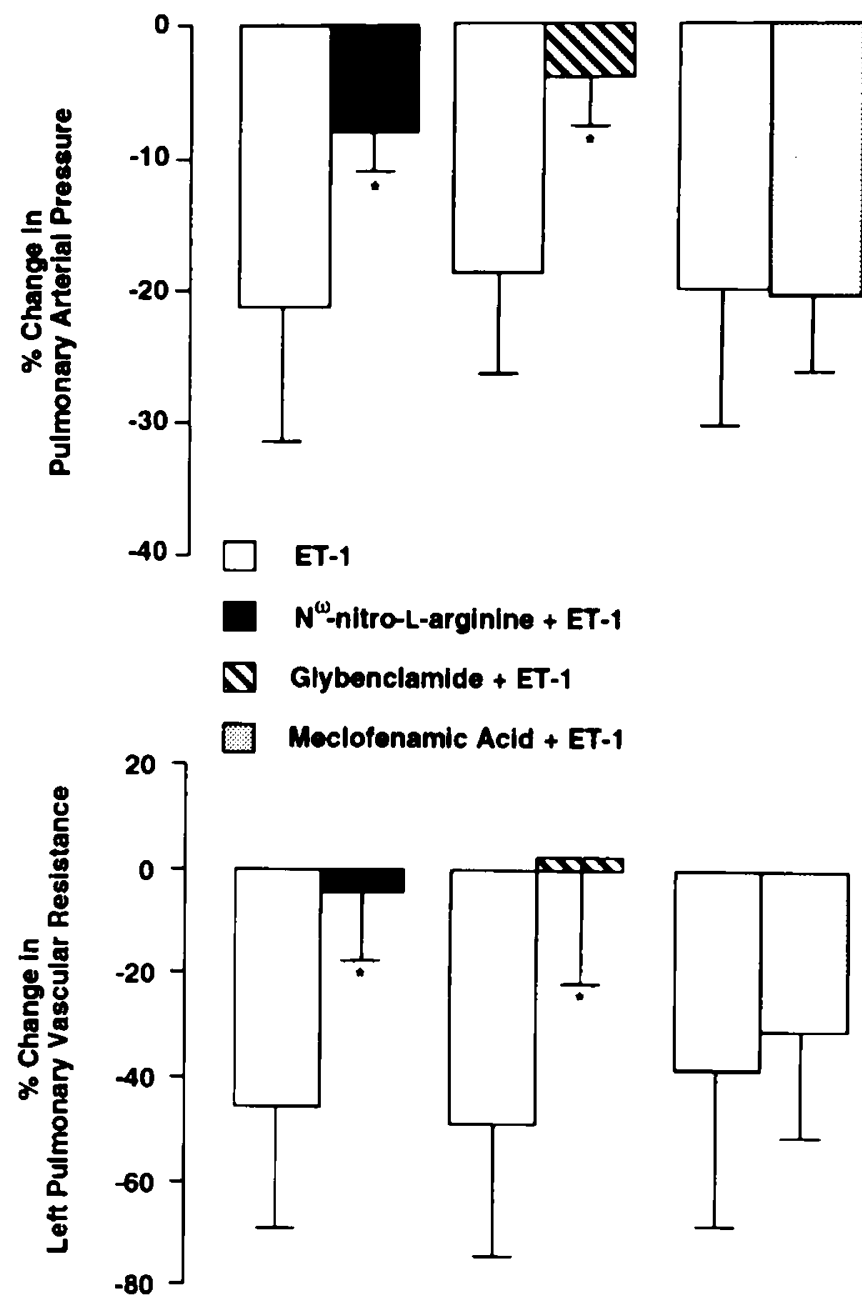

Figure 3. Effect of $\mathrm{N}^{\omega}{ }^{\omega}$-nitro-L-arginine, glybenclamide, and meclofenamic acid on the decrease in pulmonary arterial pressure (top) and left pulmonary vascular resistance (bottom) induced by ET-1 $(250 \mathrm{ng} / \mathrm{kg})$ in juvenile sheep during U46619-induced pulmonary hypertension. Values are mean $\pm \mathrm{SD}$ for six juvenile sheep given $\mathbf{N}^{\omega}$-nitro-L-arginine or glybenclamide infusions and five juvenile sheep given meclofenamic acid infusions. ${ }^{*}, p<0.05$ vs ET-1. 
nary arterial pressure $(8.7 \pm 1.9 \%$ versus $2.4 \pm 2.7 \%, p<$ $0.05)$ and left pulmonary vascular resistance $(42.5 \pm$ $13.2 \%$ versus $12.1 \pm 49.6 \%, p<0.05$ ) induced by acetylcholine was significantly attenuated.

Glybenclamide infusions during pulmonary hypertension. The infusion of glybenclamide increased mean pulmonary arterial pressure (from $17.8 \pm 2.4$ to $20.2 \pm 3.4 \mathrm{~mm}$ $\mathrm{Hg}, p<0.05$ ) and pulmonary vascular resistance (from $0.016 \pm 0.006$ to $0.019 \pm 0.007 \mathrm{~mm} \mathrm{Hg} / \mathrm{mL} / \mathrm{min}, p<$ $0.05)$. During the infusions of glybenclamide and U46619, the percent decrease in both mean pulmonary arterial pressure and left pulmonary vascular resistance induced by ET-1 were significantly attenuated (Fig. 3). Similarly, the percent decrease in mean pulmonary arterial pressure $(23.9 \pm 7.2 \%$ versus $12.9 \pm 9.4 \%, p<0.05)$ induced by cromakalim was significantly attenuated. In three sheep, the i.v. infusion of distilled water ( $\mathrm{pH} 12)$ did not change the hemodynamic variables or the hemodynamic response to ET-1 (data not shown).

Meclofenamic acid infusions during pulmonary hypertension. The infusion of meclofenamic acid did not change baseline pulmonary arterial pressure or left pulmonary vascular resistance. During the infusions of meclofenamic acid and U46619, the percent decrease in both mean pulmonary arterial pressure and left pulmonary vascular resistance induced by ET-1 was not changed (Fig. 3).

\section{DISCUSSION}

This study, in intact sheep, suggests that postnatal development alters the hemodynamic effects of ET-1 on the pulmonary circulation; the vasoconstricting effects of ET-1 are augmented and the vasodilating effects of ET-1 are attenuated with increasing age. Specifically, at rest, intrapulmonary injections of ET-1 did not change mean pulmonary arterial pressure or pulmonary vascular resistance in newborn lambs, but increased these variables in juvenile sheep. During pulmonary hypertension, ET-1 decreased mean pulmonary arterial pressure and pulmonary vascular resistance in newborn lambs and juvenile sheep, but the decrease in mean pulmonary arterial pressure was greater in the lambs. In addition, in juvenile sheep, the vasoconstricting effects of ET-1 were inhibited by meclofenamic acid (an inhibitor of prostaglandin synthesis), and the vasodilating effects of ET- 1 were attenuated by $\mathrm{N}^{\omega}$-nitro-L-arginine (an EDNO synthesis inhibitor) and glybenclamide (an ATP-dependent potassiumchannel blocker) but not by meclofenamic acid.

Our finding that postnatal development alters the hemodynamic effects of ET-1 on the pulmonary circulation both at rest and during pulmonary hypertension is consistent with previous in vitro studies in sheep. Intrapulmonary vessels of fetal and newborn lambs are less sensitive to ET-1 and have a decreased vasoconstricting response than intrapulmonary vessels of adult sheep (21). In vivo, ET-1 has induced either no effect or pulmonary vasodilation in fetuses and newborns and has induced pulmonary vasoconstriction in adult animals $(2-5,7$, $9-12,14)$. However, developmental differences cannot be delineated from species variation because newborn and adult animals of the same species have not been compared in vivo. The present study is the first to compare the developmental effects of ET-1 on the pulmonary circulation in the intact animal using the same species and experimental design in each age group. It suggests that significant alterations that result in differing responses to ET-1 occur over the first 12 mo of life in sheep and that postnatal development is one factor responsible for the wide range of hemodynamic effects of ET-1 previously reported. One potential factor that may also have contributed to the different responses was the apparent differences in resting tone between the newborn lamb and juvenile sheep. Resting left pulmonary vascular resistance was higher in the newborn lambs, which possibly favored vasodilation. Although this factor cannot be completely excluded, we found it unlikely. If calculated resting pulmonary vascular resistance is indexed to surface area (26), it is actually higher in the juvenile sheep. In addition, preliminary studies from our laboratory suggest that ET-1 produces pulmonary vasoconstriction in newborn lambs with elevated tone after lung injury (data not shown).

The postnatal alterations in the pulmonary circulation that are responsible for the changes in the hemodynamic effects of ET-1 during development are unclear. Other vasoactive agents such as prostaglandin $D_{2}$ and histamine display similar developmental changes $(27,28)$. These changes do not represent a generalized increase in vascular smooth muscle sensitivity to vasoconstricting agents with increasing age. For example, in both lambs and calves, pulmonary vasoconstriction secondary to acute alveolar hypoxia is attenuated with increasing age $(29,30)$. Similarly, in lambs, the response of small intrapulmonary arteries to vasoconstricting stimuli varied between different stimuli; some produced more vasoconstriction with increasing age and others produced less (31). Lastly, the pulmonary vascular smooth muscle contractile protein content, stress, and maximum shortening capacity are similar in newborn and adult animals (32). Altered binding or regulation of ET-1 receptors could alter the hemodynamic effects of ET-1 and may account for the changes during postnatal development. In sheep, as in other species, the receptors that mediate the hemodynamic effects of ET-1 are $\mathrm{ET}_{\mathrm{a}}$ and $\mathrm{ET}_{\mathrm{b}}$ (33). The ET receptors, located on vascular smooth muscle cells, are responsible for the vasoconstricting effects of ET-1 (33, 34). The $E_{b}$ receptors, located on the endothelial cells, may have two different functions performed by two subpopulations of receptors. One subpopulation of $E T_{b}$ receptors induces vasodilation and the other, a newly discovered $\mathrm{ET}_{\mathrm{b}}$ subpopulation, may induce vasoconstriction (35-37). In vitro studies suggest that ET-1 receptor binding in lungs and other organs change with postnatal development. For example, the density of ET binding sites in pulmonary vessels is greater in adult pigs than in 
newborns (38). In addition, there are changes in ET-1 binding sites in rat myocardium and rat brain with postnatal development (39-41). Additional studies are needed to determine the effects of postnatal development on the ET-1 receptor subpopulations and their role in mediating the changing hemodynamic effects of ET-1 throughout development.

Previous studies have shown developmental changes in vasoactive mediators such as nitric oxide and prostaglandins (42-44). In newborn lambs, we previously found that ET-1-induced pulmonary vasodilation is mediated in part by the release of endothelium-derived nitric oxide and the activation of ATP-dependent potassium channels but not by prostaglandin release (14). Therefore, the role of these mediators was investigated in juvenile sheep. In juvenile sheep, the pulmonary vasodilating effects of ET-1 during pulmonary hypertension were also attenuated by both $\mathrm{N}-{ }^{\omega}$-nitro-L-arginine and glybenclamide but not by meclofenamic acid. This suggests that nitric oxide release and potassium-channel activation mediate the pulmonary vasodilating response to ET-1 in the juvenile sheep as well. The potential independent roles of nitric oxide release and potassium-channel activation cannot be determined because previous studies suggest that they are interrelated. For example, in vitro, potassiumchannel activation is associated with nitric oxide release, and in vivo the pulmonary vasodilating effects of potassium-channel activators are attenuated by the infusion of $\mathrm{N}$ - ${ }^{\omega}$-nitro-L-arginine (45). At rest, meclofenamic acid significantly attenuated the pulmonary vasoconstricting effects of ET-1 in juvenile sheep. These results and the results of other studies suggest that the pulmonary vasoconstricting effects of ET-1 are mediated in part by prostaglandin production $(2,7,9,13,21)$. The precise role of prostaglandin production during ET-1-induced pulmonary vasoconstriction is still unknown. However, in vitro studies suggest that prostaglandin's role is greater in veins than in arteries $(13,21)$.

An unexpected finding in the juvenile sheep was that during pulmonary hypertension, ET-1 induced either vasodilation alone or a biphasic response, that is, a decrease in pulmonary arterial pressure followed by an increase in pulmonary arterial pressure. Although biphasic responses have been previously reported, why one group of juvenile sheep had vasodilation alone and one group had a biphasic response is unclear $(6,10)$. There were no differences in their baseline hemodynamic variables, weight, or sex. The pulmonary vasoconstricting component of the biphasic response is mediated by prostaglandin production, because the increase in pulmonary arterial pressure in the biphasic response was blocked by meclofenamic acid (data not shown).

Unlike our findings in the pulmonary circulation, we did not find that postnatal age altered the effects of ET-1 on the systemic circulation. The maximum increase in mean systemic arterial pressure induced by ET-1 was similar in newborn lambs and juvenile sheep. In contrast, a previous study suggested that postnatal age does alter the hemodynamic effects of ET-1 on the systemic circulation in 4-d-old to 6-wk-old lambs (46). The discrepancy in results of these studies may be related to differences in experimental design. For example, in the previous study ET-1 was injected i.v., but in the present study ET-1 was injected into the pulmonary artery.

In summary, this study shows that postnatal age alters the hemodynamic effects of ET-1 on the pulmonary circulation in sheep. The pulmonary vasoconstricting effects of ET-1 are augmented and the pulmonary vasodilating effects of ET-1 are attenuated with increasing age. The vasoconstricting effects of ET-1 are mediated by prostaglandin production; the vasodilating effects of ET-1 are mediated, in part, by the release of endothelium-derived nitric oxide and activation of ATP-dependent potassium channels. The influence of postnatal age on the effects of ET-1 in the human remain unknown. However, circulating ET-1 levels decrease with increasing age (47). We speculate that ET-1 may have an important role in regulating pulmonary vascular resistance in the developing lung. Aberrations in these normal postnatal changes may alter the balance of normal regulatory mechanisms and contribute to pulmonary hypertension disorders in children and adults.

Acknowledgments. The authors thank Mimi Zeiger for editorial assistance and Roger Chang for technical assistance.

\section{REFERENCES}

1. Yanagisawa M, Kurihara H, Kimura S, Tomobe $\mathrm{Y}$, Kobayashi M, Mitsui $\mathrm{Y}$ Yazaki Y, Goto K, Masaki T 1988 A novel potent vasoconstrictor peptide produced by vascular endothelial cells. Nature 332:411-415

2. Barnard JW, Barman SA, Adkins WK, Longnecker GL, Taylor AE 1991 Sustained effects of endothelin-1 on rabbit, dog, and rat pulmonary circulations. Am J Physiol 261:H479-H486

3. Bradley LM, Czaja JF, Goldstein RE 1990 Circulatory effects of endothelin-1 in newborn piglets. Am J Physiol 259:H1613-H1617

4. Cassin S, Kristova V, Davis T, Kadowitz P, Gause G 1991 Tone-dependent responses to endothelin in isolated perfused fetal sheep pulmonary circulation in situ. J Appl Physiol 70:1228-1234

5. Chatûeld BA, McMurtry IF, Hall SL, Abman S 1991 Hemodynamic effects of endothelin-1 on ovine fetal pulmonary circulation. Am J Physiol 261:R182R187

6. Hasunuma KD, Rodman M, O'Brien RF, McMurtry IF 1990 Endothelin-1 causes pulmonary vasodilation in rats. Am J Physiol 259:H48-H54

7. Horgan MJ, Pinherio JMB, Malik AB 1991 Mechanism of endothelin-1 in duced pulmonary vasoconstriction. Circ Res 69:157-164

8. Lippton HL, Cohen GA, McMurtry IF, Hyman AL 1991 Pulmonary vasodilation to endothelin isopeptides in vivo is mediated by potassium channe activation. J Appl Physiol 70:947-952

9. Mann J, Farrukh IS, Michael JR 1991 Mechanisms by which endothelin-1 induces pulmonary vasoconstriction in the rabbit. J Appl Physiol 71:410-416

10. Perreault T, De Marte J 1991 Endothelin-1 has a dilator effect on neonatal pig pulmonary vasculature. J Cardiovasc Pharmacol 18:43-50

11. Raffestin B, Adnot S, Eddahibi S, MacQuin-Mavier I, Braquet P, Chabrier PE 1991 Pulmonary vascular response to endothelin in rats. J Appl Physiol 70:567-574

12. Tod ML, Cassin S 1992 Endothelin-1 induced pulmonary arterial dilation is reduced by $\mathrm{N}^{\omega}$-nitro-L-arginine in fetal lambs. $\mathrm{J}$ Appl Physiol 72:1730-1734

13. Toga H, Raj JU, Hillyard R, Ku B, Anderson T 1991 Endothelin effects in isolated, perfused lamb lungs: role of cyclooxygenase inhibition and vasomotor tone. Am J Physiol 261:H443-H450

14. Wong J, Vanderford PA, Fineman JR, Chang R, Soifer SJ 1993 Endothelinproduces potent pulmonary vasodilation in the intact newborn lamb. Am J Physiol 265:H1318-H1325

15. Reid LM 1979 The pulmonary circulation: remodeling in growth and disease. Am Rev Respir Dis 119:531-546

16. Gatto C, Johnson MG, Seybold V, Kulik TJ, Lock JE, Johnson DE 1984 Distribution and quantitative developmental changes in guinea pig pulmonary $\beta$ - receptors. J Appl Physiol 57:1901-1907 
17. Shaul PW, Magness RR, Muntz KH, Debeltz D, Buja LM 1990 $\alpha_{1}$-Adrenergic receptors in pulmonary and systemic vascular smooth muscle. Alterations with development and pregnancy. Circ Res 67:1193-1200

18. Shaul PW, Muntz KH, Debeltz D, Buja LM 1991 Ontogeny of the adenylate cyclase system in the pulmonary vascular smooth muscle of the fetal lamb. J Cardiovasc Pharmacol 17:125-133

19. Shaul PW, Farrar MA, Buja LM 1991 Ontogeny of the $\beta$-adrenergic regulation of adenylate cyclase in intrapulmonary arteries from fetal and postnatal lambs. Pediatr Res 30:610-615

20. Krzeski R, Katayama H, Long W, Henry W 1992 Postnatal development attenuates endothelin-1 induced reduction in the pulmonary artery pressure in the piglet. Pediatr Res 31:62A(abstr)

21. Toga H, Ibe BO, Raj JU 1992 In vitro responses of ovine intrapulmonary arteries and veins to endothelin-1. J Appl Physiol 263:L15-L21

22. Fineman JR, Heyman MA, Soifer SJ $1991 \mathbf{N}^{\omega}$-nitro-L-arginine attenuates endothelium-dependent pulmonary vasodilation in lambs. Am J Physiol 260:H1299-H1306

23. Wong J, Vanderford PA, Winters JW, Chang R, Soifer SJ, Fineman JR 1993 Endothelin-1 does not mediate acute hypoxic pulmonary vasoconstriction in the intact newborn lamb. J Cardiovasc Pharmacol 22(suppl 8):S262-S266

24. Wallen LD, Murai DT, Clyman RI, Lee CH, Mauray FE, Kitterman JA 1986 Regulation of breathing movements in fetal sheep by prostaglandin $\mathrm{E}_{2}$. J App Physiol 60:526-531

25. Minkes RK, Kvamme P, Higuera TR, Nossaman BD, Kadowitz PJ 1991 Analysis of pulmonary and systemic vascular responses to cromakalim, an activator of $\mathrm{K}^{+}$ATP channels. Am J Physiol 260:H957-H966

26. Morrison PR, Meyer MP 1964 Biology Data Book. Federation of American of American Societies for Experimental Biology, Washington, DC, pp 120-121

27. Cassin S, Todd M, Philips J, Frisinger J, Jordan J, Gibbs C 1981 Effects of prostaglandin $D_{2}$ on perinatal circulation. Am J Physiol 240:H755-H760

28. Gordon JB, Clement de Clety S, Chu K 1991 Developmental changes in vascular responses to histamine in normoxic and hypoxic lamb lungs. J Appl Physiol 70:323-330

29. Custer JR, Hales CA 1985 Influence of alveolar oxygen on pulmonary vasoconstriction in newborn lambs versus sheep. Am Rev Respir Dis 132.326-331

30. Reeves JT, Leathers JE 1964 Circulatory changes following birth of the calf and the effect of hypoxia. Circ Res 15:343-354

31. Dunn JA, Lorch V, Sinha SN 1989 Responses of small intrapulmonary arteries to vasoactive compounds in the fetal and neonatal lamb: norepinephrine, epinephrine serotonin, and potassium chloride. Pediatr Res 25:360-363

32. Belik J, Halayko A, Rao K, Stephens N 1991 Pulmonary vascular smooth muscle: biochemical and mechanical developmental changes. J Appl Physiol 71:1129-1135
33. Solkolovsky M 1992 Endothelins and sarafotoxins: physiological regulation, receptor subtypes and transmembrane signaling. Pharmacol Ther 54:129-149

34. Arai H, Hori S, Aramori I, Ohkubo H, Nakanishi S 1990 Cloning and expression of a cDNA encoding an endothelin receptor. Nature 348:730-732

35. Sakurai T, Yanagisawa M, Takuwa $Y$, Miyazaki H, Kimura S, Goto $K$ Masaki T 1990 Cloning of a cDNA encoding a non-isopeptide-selective subtype of the endothelin receptor. Nature 348:732-735

36. Shetty SS, Toshikazu O, Webb RL, DelGrande D, Lapp RW 1993 Functionally distinct endothelin b receptors in vascular endothelium and smooth muscle. Biochem Biophys Res Commun 191:459-464

37. Solkolovsky M, Ambar I, Galron R 1992 A novel subtype of endothelin receptors. J Biol Chem 267:20551-20554

38. Hislop AA, Zhao YD, Springall DR, Polak JM, Haworth SG 1991 Endothelin binding (receptor) sites in the developing porcine pulmonary circulation. Am Rev Respir Dis 143:A404(abstr)

39. Gu XH, Ou RC, Casley DJ, Daly MJ, Nayler WG 1992 Effect of age on endothelin-1 binding sites in rat cardiac ventricular membranes. J Cardiovasc Pharmacol 19:764-769

40. Gulati A, Rebello S, Chari G, Bhat R 1992 Ontogeny of endothelin and its receptors in rat brain. Life Sci 51:1715-1724

41. Ishikawa T, Liming L, Shinmi O, Kimura S, Yanagisawa M, Groto K, Masaki T 1991 Characteristics of binding of endothelin-1 and endothelin-3 to rat hearts. Developmental changes in mechanical responses and receptor subtypes. Circ Res 69:918-926

42. Gordon JB, Hortop J, Hakim TS 1989 Developmental effects of hypoxia and indomethacin on distribution of vascular resistances in lamb lungs. Pediatr Res 26:325-329

43. Perreault T, De Marte J 1993 Maturational changes in endothelium-derived relaxations in newborn piglet pulmonary circulation. Am J Physiol 264:H302H309

44. Steinhorn RH, Morin FC, Gugino SF, Giese EC, Russel JA 1993 Developmental differences in endothelium-dependent responses in isolated ovine pulmonary arteries and veins. Am J Physiol 264:H2162-H2167

45. Chang JK, Moore P, Fineman JR, Soifer SJ, Heymann MA $1992 \mathrm{~K}^{+}$channel pulmonary vasodilation in fetal lambs: role of endothelium-derived nitric oxide. J Appl Physiol 73:188-194

46. Downing G, Gratny L, Philips C, Kadado T 1992 Systemic hemodynamic effects of endothelin-1 (ET-1) in the newborn lamb: influence of postnatal age. Clin Res 40:710A(abstr)

47. Yoshibayashi $M$, Nishioka $K$, Nakao $K$, Saito $Y$, Temma S, Matsumura $M$ Ueda T, Shirakami G, Imura H, Mikawa H 1991 Plasma endothelin levels in healthy children: high values in early infancy. J Cardiovasc Pharmacol 17:S404-S405 